\title{
Valores nutricionais de milhos de diferentes qualidades para frangos de corte ${ }^{1}$
}

\section{Cynthia Siqueira Silva ${ }^{2}$, Humberto Pena Couto ${ }^{3}$, Rony Antonio Ferreira ${ }^{3}$, José Brandão Fonseca $^{3}$, Augusto Vidal da Costa Gomes ${ }^{4}$, Rita da Trindade Ribeiro Nobre Soares ${ }^{3}$}

\author{
1 Projeto financiado pela FAPERJ. \\ 2 Mestre em Produção Animal LZNA/CCTA/UENF, Campos - RJ. \\ ${ }^{3}$ LZNA/CCTA/UENF, Campos - RJ. \\ ${ }^{4}$ DNAP/IZ/UFRRJ, Seropédica - RJ.
}

RESUMO - Este trabalho foi realizado com o objetivo de determinar os valores nutricionais de milhos de quatro qualidades, obtidos por meio de estratificação em mesa densimétrica, para frangos de corte em diferentes idades. Os milhos foram designados como: MDA - milho de densidade alta; MDI - milho de densidade intermediária; MDB - milho de densidade baixa; e MDT milho de densidade total, composto de 30\% de MDA, 60\% de MDI e 10\% de MDB. Dois ensaios biológicos foram conduzidos utilizando-se o método tradicional de coleta total de excretas para determinação da energia metabolizável aparente corrigida (EMAn). O primeiro ensaio metabólico foi conduzido com pintos Cobb de 11 a 19 dias e o segundo, com pintos de 29 a 37 dias de idade. Foram realizadas análises químicas para determinação do perfil nutricional, classificação de grãos segundo a densidade e comparação por meio das estimativas de equações de predição do valor energético e de micotoxinas. Os perfis de aminoácidos digestíveis dos milhos foram estimados pelo NIR. Os valores da EMAn dos milhos de diferentes qualidades (MDA, MDI, MDB e MDT) determinados com frangos na fase inicial foram: 3.308; 3.121; 2.937 e $3.239 \mathrm{kcal} / \mathrm{kg}$ e, para a fase de crescimento: $3.413,3.362,3.174$ e $3.348 \mathrm{kcal} / \mathrm{kg}$, respectivamente. Esses valores comprovam as significativas perdas energéticas dos milhos de mais baixa qualidade e a eficiência da mesa densimétrica em estratificar os grãos. A diferença da EMAn entre as idades das aves sugere melhor eficiência de utilização da energia com o avanço da idade. As equações de predição podem ser utilizadas para estimar o valor energético de milhos, tanto por sua classificação como pela densidade. Entretanto, o erro sistemático associado a cada equação de predição pode comprometer a exatidão de seu valor nutricional. As contaminações por aflatoxinas e tricotecenos variam com a qualidade do milho estratificado, fator importante a ser considerado na alimentação de frangos de corte.

Palavras-chave: aminoácidos, densidade, energia metabolizável, micotoxinas

\section{Nutritional value of corn with different qualities for broiler chicken}

ABSTRACT - This work was carried out to determine the nutritional value of corn of different qualities, obtained by means of stratification in densimetric table, for broilers in different ages. The corns were designed as: MDA - high density corn; MDI - medium density corn; MDB - low density corn and MDT - total density corn, composed by 30\% MDA, 60\% MDI and $10 \%$ MDB. Two biological assays were carried out using the traditional total excreta collection method to determine the apparent metabolizable energy corrected by nitrogen balance $\left(\mathrm{AME}_{\mathrm{N}}\right)$. The first assay was carried out using Cobb chicks with 11 to 19 days old and in the second assay, with chicks with 29 to 37 days old. Chemical analyses were made to estimate the nutritional profile, classification of the grains according to density and comparison by means of prediction equation estimatives the energy values and mycotoxins. The digestible amino acids profiles were obtained by NIR. The values of $\mathrm{AME}_{\mathrm{N}}$ of corns of different qualities (MDA, MDI, MDB and MDT) for broilers in initial phase were respectively: 3308; 3121; 2937 and $3239 \mathrm{kcal} / \mathrm{kg}$; and broilers in growing phase were respectively: 3413, 3362, 3174 and $3348 \mathrm{kcal} / \mathrm{kg}$. These results indicated significant energy losses of low density corn and the efficiency of the densimetric table to stratify the grains by quality. The different $\mathrm{AME}_{\mathrm{N}}$ values between birds ages suggest better energy utilization efficiency as age increases. The prediction equations could be used to estimate energy value of corn by its classification or density. However, the error associated to each prediction equation could compromise the accuracy of the nutritional value. The contaminations by aflatoxins and trichothecenes changed with quality of the stratified corn, important factor to be considered in the broilers feeding.

Key Words: aminoacids, density, metabolizable energy, mycotoxins

Este artigo foi recebido em 18/12/2006 e aprovado em 30/10/2007. 


\section{Introdução}

Na formulação de rações, é fundamental conhecer o valor nutritivo dos alimentos. Para isso, devem ser determinadas a composição química, a disponibilidade dos nutrientes e a concentração energética dos alimentos. A energia (produto resultante da transformação dos nutrientes pelo metabolismo animal) presente nos alimentos, o valor energético dos alimentos e as exigências de energia das aves têm sido expressos em forma de energia metabolizável aparente (Albino et al., 1992).

Segundo Albino (1991), a determinação dos valores de energia metabolizável dos alimentos é de grande importância, pois é a mais utilizada no cálculo de rações para aves. A precisão desses valores está diretamente relacionada ao sistema de determinação utilizado, portanto, é essencial para que se minimizem erros de estimativas. A exatidão e a precisão na estimativa dos valores de energia metabolizável são essenciais para maximizar o desempenho das aves e proporcionar melhor ganho de peso e eficiência alimentar (Dale 1992).

A grande variação na composição química dos alimentos pode causar alterações significativas nos valores de digestibilidade da proteína e energia dos ingredientes (Fialho et al., 1995). A utilização mais exata dos valores energéticos dos alimentos otimiza a produtividade e maximiza a rentabilidade avícola. A informação mais exata e precisa do perfil de aminoácidos dos alimentos é essencial para a formulação de custo mínimo, redução dos riscos de suprimento de níveis marginais ou em excesso dos aminoácidos essenciais dietéticos e, conseqüentemente, diminuição dos custos de alimentação e excreção de nitrogênio para o meio ambiente.

Na área de produção de rações, muitos esforços têm sido realizados para desenvolver novas tecnologias que proporcionem benefícios na melhoria da qualidade nutricional dos alimentos utilizados na alimentação das aves. A expansão e a peletização das rações são exemplos destas tecnologias, assim como a estratificação de grãos utilizando-se a mesa densimétrica ou gravimétrica, que garante produtos de melhor qualidade nutricional.

Neste trabalho, estudaram-se os valores nutricionais de milhos de quatro qualidades para frangos de corte nas fases inicial e crescimento.

\section{Material e Métodos}

Os ensaios biológicos foram realizados no setor de avicultura da Unidade de Apoio à Pesquisa do Laboratório de Zootecnia e Nutrição Animal da Universidade Estadual do Norte Fluminense, localizada em Campos dos Goytacazes, Rio de Janeiro.

Os valores de energia metabolizável aparente e aparente corrigida foram determinados utilizando-se o método tradicional de coleta total de excretas. Foram avaliados quatro tipos de milho, três originados diretamente da estratificação dos grãos em mesa densimétrica (Zampronio, Modelo Z-75): MDA - milho de densidade alta; MDI - milho de densidade intermediária; MDB - milho de densidade baixa; e MDT milho de densidade total, fração composta de 30\% de MDA, $60 \%$ de MDI e 10\% de MDB, utilizada para simular a composição do milho não estratificado pela mesa densimétrica. A estratificação dos grãos foi realizada na fábrica de rações da Reginaves Indústria e Comércio de Aves Ltda (RICA), localizada no estado do Rio de Janeiro.

Para elaboração da matriz nutricional dos milhos de diferentes qualidades, realizou-se uma série de análises bromatológicas para determinação dos valores de matéria seca (MS), proteína bruta (PB), extrato etéreo (EE), fibra bruta (FB), matéria mineral (MM), extrato não-nitrogenado (ENN), cálcio (Ca) e fósforo total (Pt).

Os perfis de aminoácidos totais e digestíveis foram analisados pelo método de Espectroscopia de Refletância no Infravermelho Próximo (NIR), realizado pelo Laboratório CEAN - ADISSEO, segundo curvas-padrão propostas pelo Rhodimet ${ }^{\mathrm{TM}}$ NIRSA. O método da fatoração foi utilizado para corrigir os níveis de aminoácidos digestíveis da matriz nutricional dos milhos de diferentes qualidades, por meio da relação entre eles e a proteína bruta obtidas pelas análises no NIR.

Utilizando os padrões do Ministério da Agricultura, Pecuária e Abastecimento (MAPA), foram realizadas análises físicas de classificação de grãos de várias amostras dos diferentes tipos de milho estratificados considerando: grãos quebrados, ardidos, carunchados, chochos, impurezas/ fragmentos e materiais estranhos. Os resultados da classificação foram utilizados para estimar os valores energéticos dos milhos de diferentes qualidades por meio de equações de predição descritas na literatura e comparadas aos resultados obtidos nos ensaios metabólicos.

A densidade dos milhos foi avaliada utilizando-se a metodologia do peso hectolítrico, pela qual os produtos são diferenciados pela mesa densimétrica, que estratifica o cereal pela densidade ou pelo peso específico.

Baidoo et al. (1991) apresentaram a equação de predição para a estimativa da EMVn $(\mathrm{kcal} / \mathrm{kg}$ MS $)=1,452+0,566$ x Densidade (kg/hl) de diferentes lotes de milho. Esta equação foi utilizada para estimar o valor energético, com as densidades e a matérias secas obtidas dos milhos estudados, 
considerando-se a diferença média entre a EMVn e a EMAn de $12 \%$ (Lima, 2000).

Os ensaios de metabolismo 1 e 2 foram realizados utilizando-se o método de coleta total de excretas com frangos de corte em dois diferentes períodos: fase inicial (11 a 19 dias de idade) e fase de crescimento (29 a 37 dias de idade). Em ambos os ensaios, foram utilizados os mesmos milhos de diferentes qualidades, que substituíram em $40 \%$ uma dieta-referência à base de milho e farelo de soja, formulada para satisfazer às exigências das aves nas fases inicial e de crescimento.

As exigências das aves e a composição química dos alimentos, com exceção dos diferentes milhos estudados, foram determinadas com base nas Tabelas Brasileiras para Aves e Suínos (Rostagno et al., 2005). Foram utilizados 150 pintos de corte da linhagem Cobb, sexados, com peso médio de $252 \mathrm{~g}$ (15 dias de idade). As aves foram inicialmente alojadas em boxes $(1,80 \times 1,80 \mathrm{~m})$ em um galpão experimental até que se completasse o período de transferência para as baterias onde foi realizado o ensaio de metabolismo.

No $11^{\mathrm{O}}$ dia de idade, os pintos foram transferidos para uma bateria metálica com 25 divisões $(0,50 \times 1,00 \mathrm{~m})$, alocada em galpão de alvenaria coberto com telhas de barro e contendo um bebedouro automático tipo taça e um comedouro linear em cada divisão. Até o 15o dia de idade, todas as aves foram alimentadas com ração inicial contendo $3.000 \mathrm{kcal}$ de EM/kg e 21\% PB.

O delineamento experimental foi o inteiramente casualizado, com cinco tratamentos, compostos de quatro alimentos-teste e uma ração-referência, cinco repetições e seis aves (três machos e três fêmeas) por unidade experimental. O período do $11^{\circ}$ ao $14^{\circ}$ dia de idade (quatro dias) foi destinado à adaptação às instalações e às rações experimentais e, do 15 o ao 190 dia (cinco dias), à coleta total de excretas. Como marcador fecal, utilizou-se óxido de ferro a 1\% nas dietas 12 horas antes do início das coletas de excretas e antes do término do período experimental. As excretas foram coletadas em bandejas revestidas com material plástico dispostas sob cada gaiola. Foram realizadas duas coletas ao dia, às 8 e às $17 \mathrm{~h}$, para evitar fermentações fecais. Ao final do período experimental, foi quantificada a ração consumida por unidade experimental.

As excretas diariamente coletadas foram acondicionadas em sacos plásticos devidamente identificados e armazenadas em freezer até o final do período. Ao término do primeiro ensaio de metabolismo, as aves foram transferidas para os boxes experimentais do galpão de alvenaria até atingirem a idade para o início do segundo ensaio. Neste período, foi fornecida à vontade ração de crescimento com $3.150 \mathrm{kcal} \mathrm{EM} / \mathrm{kg}$ e $18,5 \%$ PB.
No ensaio 2, foram utilizadas as mesmas aves para manutenção dos tratamentos impostos no ensaio 1. As aves com peso médio de $1,7 \mathrm{~kg}$ (29 dias de idade) foram alojadas em gaiolas próprias para estudos de metabolismo $(50 \times 50 \times 50 \mathrm{~m})$, providas de comedouro linear individual e bebedouros do tipo nipple. O delineamento experimental foi inteiramente casualizado, com cinco tratamentos, compostos de quatro alimentos-teste e uma ração-referência, cinco repetições e dois animais (um macho e uma fêmea) por unidade experimental.

De forma semelhante ao primeiro período experimental, as aves passaram por quatro dias de adaptação às gaiolas e às rações-teste ( $29^{\circ}$ ao $32^{\circ} \underline{0}$ dia), seguidos de cinco dias de coleta das excretas ( $33^{\circ}$ ao 370 dia). As excretas diariamente coletadas foram acondicionadas em sacos plásticos, pesadas e congeladas, segundo os mesmos procedimentos do primeiro período, e submetidas a análises laboratoriais, realizadas segundo Silva (1990).

Posteriormente, as amostras foram descongeladas, pesadas e homogeneizadas para retirada de subamostras para análises laboratoriais. As análises dos teores de matéria seca, nitrogênio e energia bruta foram realizadas após présecagem em estufa ventilada a $55^{\circ} \mathrm{C}$ (Calorímetro adiabático - Tipo Parr). Os valores de energia metabolizável aparente (EMA) e aparente corrigida pelo balanço de nitrogênio (EMAn) foram calculados utilizando-se as equações propostas por Matterson et al. (1965).

Nos milhos e nas rações utilizadas em ambos os ensaios de metabolismo, realizaram-se análises das micotoxinas aflatoxina e tricotecenos nos milhos, com base na metodologia de cromatografia em camada delgada.

Para avaliar as condições ambientais em que foram mantidos os animais, foram registradas diariamente as temperaturas de máxima e mínima.

Os tratamentos consistiram de uma ração-referência (Tabela 1) e de quatro outras rações, obtidas pela substituição de 40\% da ração-referência pelos milhos de densidade alta (MDA), intermediária (MDI) ou baixa (MDB) ou de densidade total (MDT).

\section{Resultados e Discussão}

Houve grandes diferenças entre os valores de EMA e EMAn entre os tipos de milho estudados (Tabela 2), o que está relacionado às variações na sua composição bromatológica. Os valores obtidos também diferiram significativamente entre as duas fases estudadas $(\mathrm{P}<0,05)$.

Em ambos os ensaios, os valores de EMA e a EMAn decresceram à medida que a densidade do milho reduziu, refletindo sua pior qualidade. O MDA foi energeticamente 
Tabela 1 - Composição percentual da ração-referência

\begin{tabular}{|c|c|c|}
\hline \multirow[t]{2}{*}{ Ingrediente (\%) } & \multicolumn{2}{|c|}{ Ração-referência } \\
\hline & Inicial & Crescimento \\
\hline Milho & 57,928 & 64,129 \\
\hline Farelo de soja & 35,670 & 29,100 \\
\hline Fosfato bicálcico & 1,830 & 1,620 \\
\hline Calcário & 0,905 & 0,790 \\
\hline Óleo de soja & 2,387 & 3,200 \\
\hline Sal comum & 0,420 & 0,411 \\
\hline DL-metionina (99\%) & 0,268 & 0,205 \\
\hline L-lisina.HCl $(78,4 \%)$ & 0,120 & 0,135 \\
\hline L-treonina $(98,5 \%)$ & 0,062 & - \\
\hline Premix $^{1}$ & 0,400 & 0,400 \\
\hline Antioxidante (\%) & 0,010 & 0,010 \\
\hline Total & 100,00 & 100,00 \\
\hline \multicolumn{3}{|l|}{ Composição calculada } \\
\hline EM (kcal/kg) & 2950 & 3150 \\
\hline Proteína bruta (\%) & 21,5 & 18,5 \\
\hline Metionina digestível (\%) & 0,56 & 0,48 \\
\hline Metionina + Cistina digestível (\%) & 0,85 & 0,75 \\
\hline Lisina digestível (\%) & 1,31 & 1,00 \\
\hline Cálcio (\%) & 0,90 & 0,80 \\
\hline Fósforo disponível (\%) & 0,45 & 0,39 \\
\hline \multicolumn{3}{|c|}{ 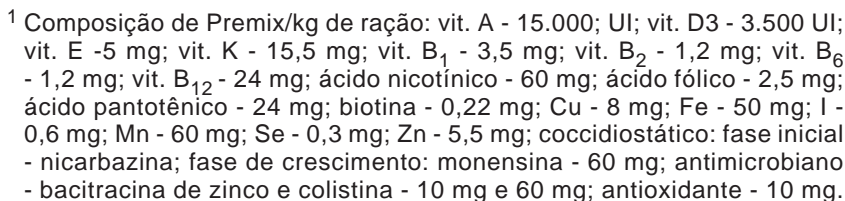 } \\
\hline
\end{tabular}

superior ao MDI e ao MDB aproximadamente 6,0 e 12,5\% na fase inicial e de 1,5 e $7,5 \%$ na fase de crescimento, respectivamente. O MDT, que simula a composição do milho não estratificado pela mesa densimétrica, apresentou valores de energia semelhantes ao MDI. Esses resultados comprovam a eficiência da estratificação pela mesa densimétrica e que os frangos jovens são menos eficientes que os mais velhos no aproveitamento do milho de pior qualidade. Esse maior aproveitamento energético se deve à menor taxa de passagem e ao maior tempo de permanência dos alimentos no trato gastrointestinal das aves mais velhas, que favorece a ação das enzimas digestivas aumentando a digestibilidade dos nutrientes (Nascimento et al., 2005).

Segundo Albino et al. (1982) e Rostagno et al. (1997), as aves adultas utilizam mais energia que as jovens, pois alguns nutrientes são melhor metabolizados por aves adultas. Entretanto, Albino et al. (1986) não encontraram diferenças nos valores de energia metabolizável de alguns alimentos estudados em diferentes idades. Nascimento et al. (2005) também não encontraram diferenças nos valores de EMAn de várias farinhas de vísceras determinado em aves jovens e adultas, entretanto, o mesmo não ocorreu com as farinhas de penas.
Tabela 2 - Valores de energia metabolizável (kcal/kg) dos milhos de diferentes qualidades

\begin{tabular}{lccccc}
\hline \multirow{2}{*}{ Tipo milho } & \multicolumn{2}{c}{ EMA } & & \multicolumn{2}{c}{ EMAn } \\
\cline { 2 - 3 } \cline { 6 - 6 } & Ensaio 1 & Ensaio 2 & & Ensaio 1 & Ensaio 2 \\
\hline MDA & 3.518 & 3.563 & & 3.308 & 3.413 \\
MDI & 3.356 & 3.507 & & 3.121 & 3.362 \\
MDB & 3.131 & 3.279 & & 2.937 & 3.174 \\
MDT & 3.449 & 3.479 & & 3.239 & 3.348 \\
\hline
\end{tabular}

$1=15$ a 19 dias de idade.

$2=33$ a 37 dias de idade.

As diferenças entre os valores energéticos dos milhos de diferentes qualidades determinadas em frangos de corte de diferentes idades sugerem a necessidade de avaliação da energia metabolizável de vários outros alimentos importantes na alimentação dos frangos de corte. Futuramente, as tabelas de composição nutricional apresentarão os valores energéticos dos alimentos de acordo com as fases de criação.

Considerando os valores de proteína bruta (Tabela 3) obtidos nos milhos de diferentes qualidades, pode-se inferir que o MDB possui maior teor protéico que o MDI, que, por sua vez, é superior ao MDA. Em razão da menor concentração de amido nos grãos de menor peso específico, espera-se maior concentração dos outros nutrientes. Dale (1995) obteve resultado maior para o teor protéico do milho contaminado por fungos e verificou que as frações de mais baixa densidade possuem maior contaminação fúngica, em decorrência da maior concentração de pó.

Os percentuais de grãos ardidos, quebrados e chochos, de impurezas/fragmentos e material estranho aumentaram à medida que a densidade dos grãos de milho estudados diminuiu. A classificação demonstrou alta eficiência na separação dos grãos de milho pela mesa densimétrica de acordo com sua qualidade, originando produtos diferenciados quanto ao seu valor nutricional.

O MDA foi classificado como o melhor tipo (Tabela 4), confirmando que densidade mais alta dos grãos de milho proporciona níveis maiores de energia metabolizável para os frangos de corte, como observado nos ensaios de metabolismo 1 e 2. O aumento expressivo do percentual de grãos ardidos e chochos, de fragmentos e impurezas e de material estranho, principalmente para o MDB, explica as grandes perdas de EM obtidas no ensaio de metabolismo em ambas as fases de crescimento. Os valores da classificação para o MDT, que simula o grão não submetido à mesa densimétrica, foram muito próximos dos resultados obtidos para o MDI.

A partir dos resultados de classificação obtidos neste trabalho, foram estimadas as perdas de energia metabolizável (Tabela 5) utilizando-se a equação proposta por Rostagno 
Tabela 3 - Composição bromatológica e de aminoácidos digestíveis dos milhos avaliados

\begin{tabular}{lcccc}
\hline & MDA & MDI & MDB & MDT \\
\hline Nutriente (\%) & & & & \\
PB & 8,38 & 8,63 & 9,00 & 8,43 \\
EE & 4,35 & 4,37 & 5,08 & 4,44 \\
FB & 2,17 & 2,20 & 5,67 & 2,54 \\
MM & 1,05 & 1,10 & 1,60 & 1,14 \\
ENN & 70,50 & 70,56 & 65,78 & 70,23 \\
Ca & 0,06 & 0,07 & 0,06 & 0,07 \\
Pt & 0,23 & 0,23 & 0,29 & 0,24 \\
\hline Aminoácido digestível & ( ) & & & \\
\hline Lisina & 0,217 & 0,226 & 0,250 & 0,228 \\
Metionina & 0,178 & 0,164 & 0,160 & 0,166 \\
Metionina + Cistina & 0,306 & 0,267 & 0,260 & 0,270 \\
Treonina & 0,267 & 0,226 & 0,220 & 0,228 \\
Triptofano & 0,045 & 0,041 & 0,040 & 0,042 \\
Valina & 0,379 & 0,339 & 0,369 & 0,353 \\
Isoleucina & 0,295 & 0,262 & 0,270 & 0,270 \\
Leucina & 1,031 & 0,925 & 0,928 & 0,940 \\
Fenilalanina & 0,384 & 0,329 & 0,354 & 0,353 \\
Histidina & 0,201 & 0,195 & 0,180 & 0,192 \\
Arginina & 0,401 & 0,344 & 0,329 & 0,358 \\
\hline
\end{tabular}

et al. (2005), que considera as frações classificatórias $($ Emp $=-0,064+1,56$ QBR + 6,98 FRIM + 10,06 FUN + 12,28 INS + 5,87ADC), em que: Emp = energia metabolizável perdida para aves, kcal/kg; QBR = grãos quebrados, em \%; FRIM = fragmentos de grãos e impurezas, em \%; FUN = grãos atacados por fungos; INS = grãos atacados por insetos; e ADC = grãos atacados por diversas causas, \%.

A equação de predição estimou grandes perdas nos valores de EM entre os milhos, em virtude das variações das frações da classificação. As perdas energéticas aumentaram à medida que a qualidade do milho piorou. As estimativas foram aproximadamente: 94; 200; 336 e 161 kcal/kg de milho para o MDA, MDI, MDB e MDT, respectivamente. As perdas mais significativas foram decorrentes da presença de grãos quebrados e ardidos e de matérias estranhas e impurezas, principalmente para o MDI e MDB.

Esses resultados corroboram informações de Dale (1996) de que grãos de milho quebrados e as matérias estranhas nele contidos reduzem significativamente o valor da energia metabolizável verdadeira para aves em 5,6 e 17,0\%, respectivamente.

Na Tabela 6 consta uma comparação dos valores de energia metabolizável obtidos nos ensaios de metabolismo 1 e 2, preditos pela equação proposta por Rostagno et al. (2005) e corrigidos com base no milho tipo “0” (qualidade excelente), aos valores para os milhos tipos 1 , 2 e 3 propostos pelas Tabelas Brasileiras de Aves e Suínos (2005).

Os valores energéticos do MDA e MDI determinados no ensaio de metabolismo realizado com frangos de 29 a 37
Tabela 4 - Classificação dos milhos avaliados

\begin{tabular}{lcccc}
\hline Fração (\%) & MDA & MDI & MDB & MDT \\
\hline Quebrados & 8,45 & 44,09 & 57,89 & 35,21 \\
Ardidos & 2,33 & 6,95 & 6,80 & 4,07 \\
Carunchados & 3,25 & 0,78 & 1,04 & 1,04 \\
Chochos & 0,88 & 3,08 & 5,74 & 3,32 \\
Imp./fragmento & 1,52 & 3,83 & 9,24 & 2,76 \\
Material estranho & 0,00 & 0,28 & 9,61 & 1,34 \\
\hline
\end{tabular}

dias de idade foram muito semelhantes aos propostos para os tipos 1 e 2, entretanto, foram inferiores aos do tipo 3 para o MDB. No ensaio de metabolismo com pintos de 11 a 19 dias de idade, todos os valores foram inferiores à classificação por tipo proposta pelas Tabelas Brasileiras.

A comparação dos valores energéticos dos ensaios de metabolismos aos obtidos pela equação de predição das perdas energéticas demonstrou valores mais próximos das EMAn obtidas no ensaio com pintos jovens. Os resultados de densidade para os diferentes tipos de milho (MDA, MDI e MDB) estratificados pela mesa densimétrica utilizando-se o método do peso hectolítrico foram: 805,10; 736,63 e $592,93 \mathrm{~kg} / \mathrm{m}^{3}$, respectivamente.

A média da densidade para o MDA foi 9,3 e 35,8\% superior às observadas para o MDI e o MDB, respectivamente. Portanto, o milho com maior densidade, ou seja, maior peso por unidade de volume, possui maior valor energético, em virtude de seu maior conteúdo de amido e menor de impurezas, fragmentos e materiais estranhos, que aumentam o valor de fibra bruta.

Os resultados obtidos pela equação de Baidoo et al. (1991) para a estimativa do valor energético de acordo com as densidades e a matérias secas obtidas dos milhos estudados foram: 3.462, 3.187 e $2.574 \mathrm{kcal} / \mathrm{kg}$ para o MDA, MDI e MDB, respectivamente, semelhantes ao encontrado no ensaio de metabolismo para o MDA, que foi inferior ao MDI e ao MDB aproximadamente 300 e $700 \mathrm{kcal} / \mathrm{kg}$, respectivamente. Essa equação estimou melhor o valor energético do milho de boa qualidade e subestimou o valor dos milhos de mais baixa qualidade.

Verificou-se crescente aumento, tanto de aflatoxinas quanto de tricotecenos, à medida que piorou a qualidade do milho, expressa pela classificação e densidade (Tabela 7). Entre os milhos avaliados, o de baixa densidade apresentou os maiores teores de contaminação, tanto de aflatoxinas quanto de tricotecenos, o que está relacionado à maior presença de pó segregado pela mesa densimétrica.

As análises de micotoxinas comprovaram contaminação fúngica das rações produzidas com os milhos (Tabela 8). Os fungos, ao se desenvolverem nos grãos, utilizam nutrientes do alimento alterando significativamente seu 
Tabela 5 - Estimativa das perdas dos valores energéticos $(\mathrm{kcal} / \mathrm{kg})$ pela equação de predição

\begin{tabular}{|c|c|c|c|c|c|c|c|}
\hline Milho & Quebrados & Imp/Frag & Ardidos & Carunchados & Chochos & Mat. Est. & EMAn \\
\hline MDI & 71,43 & 26,71 & 69,95 & 9,58 & 21,50 & 1,66 & 200,76 \\
\hline MDT & 57,03 & 19,29 & 40,98 & 12,81 & 23,20 & 7,89 & 161,13 \\
\hline
\end{tabular}

Tabela 6 - Comparação dos valores de energia metabolizável dos milhos avaliados

\begin{tabular}{lcccc}
\hline Tipo milho & \multicolumn{4}{c}{ Energia metabolizável aparente corrigida (EMAn) } \\
\cline { 2 - 5 } & Ensaio $^{1}$ & Ensaio ${ }^{2}$ & Equação de predição & Tabelas brasileiras \\
MDA & 3.308 & 3.413 & 3.338 & $3.403-$ Tipo 1 \\
MDI & 3.121 & 3.362 & 3.232 & $3.381-$ Tipo 2 \\
MDB & 2.937 & 3.174 & 3.096 & $3.343-$ Tipo 3 \\
MDT & 3.239 & 3.348 & 3.271 & 3.381 \\
\hline
\end{tabular}

Ensaio $^{1:} 15$ a 19 dias; Ensaio 2 : 33 a 37 dias de idade.

Tabela 7 - Análises de micotoxinas dos milhos avaliados

\begin{tabular}{lcc}
\hline Tipo milho & Aflatoxinas $(\mathrm{ppb})$ & Tricotecenos $(\mathrm{ppb})$ \\
\hline MDA & 0,00 & 26,4 \\
MDI & 79,0 & 61,5 \\
MDB & 115,5 & 98,5 \\
MDT & 72,58 & 35,2 \\
\hline
\end{tabular}

Tabela 8 - Avaliação de micotoxinas nas rações dos ensaios de metabolismo

\begin{tabular}{lccccc}
\hline Ração & \multicolumn{2}{c}{ Aflatoxinas $(\mathrm{ppb})$} & & \multicolumn{2}{c}{ Tricotecenos $(\mathrm{ppb})$} \\
\cline { 2 - 3 } \cline { 5 - 6 } & 1 & 2 & & 1 & 2 \\
\hline Ração 1 - MDA & 5,16 & 1,69 & & 185,0 & 176,4 \\
Ração 2 - MDI & 0,92 & 6,68 & & 348,5 & 182,7 \\
Ração 3 - MDB & 5,06 & 15,47 & & 505,9 & 214,8 \\
Ração 4 - MDT & 1,77 & 9,73 & & 223,7 & 191,3
\end{tabular}

Ensaio $^{1:} 15$ a 19 dias; Ensaio2: 33 a 37 dias de idade.

valor nutritivo. Estudos comprovam a correlação entre o crescimento do fungo e a redução do nível energético do grão. Segundo Zaviezo et al. (2005), a contaminação por micotoxinas promove redução de 4 a $5 \%$ do valor da energia metabolizável para aves.

Os resultados obtidos nas rações experimentais confirmam que os níveis de aflatoxina não são tão preocupantes quanto os de tricotecenos, que atualmente têm se tornado a micotoxina de maior importância para a avicultura. Essas micotoxinas prejudicam o desempenho zootécnico de frangos de corte e têm efeito de suprimir o sistema imune, aumentando a susceptibilidade às doenças, principalmente pela menor resposta às vacinações.

As temperaturas médias de máxima e mínima registradas durante o período experimental foram de 29,0 e $24,0^{\circ} \mathrm{C}$ para o primeiro ensaio e 32,9 e $24,0^{\circ} \mathrm{C}$ para o segundo. Durante o primeiro ensaio de metabolismo, quando as aves se encontravam na fase inicial, houve um período de temperaturas mínimas inferiores às adequadas para a idade, enquanto, no ensaio 2 , foram verificadas temperaturas de máxima elevadas para o conforto térmico dos frangos de corte.

\section{Conclusões}

Os valores da EMAn dos milhos de diferentes qualidades estratificados em mesa densimétrica (MDA, MDI, MDB) determinados com frangos de 15 a 19 dias foram $3.308 ; 3.121$ e $2.937 \mathrm{kcal} / \mathrm{kg}$ e, para a idade de 33 a 37 dias, 3.413, 3.362, 3.174 e $3.348 \mathrm{kcal} / \mathrm{kg}$, respectivamente. Os valores de EMAn, proteína bruta e aminoácidos devem ser diferenciados para elaboração da composição nutricional dos milhos de diferentes qualidades que serão utilizados na formulação de rações de custo mínimo. As equações de predição podem ser utilizadas para estimar o valor energético de milhos de diferentes qualidades, tanto por sua classificação como pela densidade ou composição química. Entretanto, o erro sistemático associado a cada equação pode comprometer a exatidão do seu valor nutricional. As contaminações por aflatoxinas e tricotecenos variam com a qualidade do milho estratificado, fator importante a ser considerado nas diferentes fases de alimentação de frangos de corte.

\section{Literatura Citada}

ALBINO, L.F.T.; FERREIRA, A.S.; FIALHO, E.T. et al. Determinação dos valores de energia metabolizável e matéria seca aparentemente metabolizável de alguns alimentos. Revista da Sociedade Brasileira de Zootecnia, v.11, n.2, p.207-220, 1982. 
ALBINO, L.F.T.; COELHO, M.G.R.; RUTZ, F. al. Valores energéticos de alguns alimentos determinados em aves jovens e adultas. In: REUNIÃO ANUAL DA SOCIEDADE BRASILEIRA DE ZOOTECNIA, 1986, Campo Grande. Anais... Campo Grande: Sociedade Brasileira de Zootecnia, 1986. p.70.

ALBINO, L.F.T. Sistemas de avaliação nutricional de alimentos e suas aplicações na formulações de rações para frango de corte. Viçosa, MG: Universidade Federal de Viçosa, 1991. 141p. Tese (Doutorado em Zootecnia) - Universidade Federal de Viçosa, 1991.

ALBINO, L.F.T.; ROSTAGNO, H.S.; TAFURI, M.L. Utilização de diferentes sistemas de avaliação energética de alimentos na formulação de rações para frangos de corte. Revista da Sociedade Brasileira de Zootecnia, v.21, n.6, p.10371046, 1992.

BAIDOO, S.K.A.; SHERES, A.; ROBBLEE, A.R. Effect of kernel density on the on the apparent and true metabolizable energy value of corn for chikens. Poultry Science, v.70, p.2102-2107, 1991.

BIAGI, J.D.; SILVA, L.O.N.; MARTINS, R.R. Importância da qualidade de grãos na alimentação animal. In: SIMPÓSIO LATINO-AMERICANO DE NUTRIÇÃO ANIMAL E SEMINÁRIO SOBRE TECNOLOGIA DE PRODUÇÃO DE RAÇÕES, 1996, Campinas. Anais... Campinas: Colégio Brasileiro de Nutrição Animal, 1996. p.21-45.

DALE, N. Formulacion de dietas sobre la base de disponibilidad de aminoácidos. Avicultura Profissional, v.9, n.3, p.120-122, 1992.

DALE, N.M. Ingredient analysis table. Feedstuffs Reference Issue. Minnetonka: Miller Publishing Co., 1995.
FIALHO, E.T.; BARBOSA, H.P.; ALBINO, L.F.T. Chemical composition, digestible protein and energy values of some alternative feedstuffs for pigs in Brazil. Animal Feed Science and Techonology v.55, n.3-4, p.239-245, 1995.

LIMA, G.J.M.M.; SINGER, J.M.; GUINONI, A.L. et al. Classificação do milho, quanto à composição em alguns nutrientes através do emprego de análises e conglomerados. In: CONGRESSO NACIONAL DE MILHO E SORGO, 2000, Uberlândia. Anais... Uberlândia: ABMS, 2000. (CD-ROM).

MATTERSON, L.D.; POTTER, L.M.; STUTZ, N.W. et al. The metabolizable energy of feed ingredients for chickens. Agricultural Experiment Station Research Report, v.7, p.3-22, 1965.

NASCIMENTO, A.H.; GOMES, P.C.; ROSTAGNO, H.S. et al. Valores de energia metabolizável de farinha de penas e de vísceras determinados com diferentes níveis de inclusão e duas idades de aves. Revista Brasileira de Zootecnia, v.34, n.3, p.877-881 2005.

RODRIGUES, P.B.; ROSTAGNO, H.S.; ALBINO, L.F.T. Valores energéticos do milheto, do milho e subprodutos do milho, determinados com frangos de corte e galos adultos. Revista Brasileira de Zootecnia, v.31, n.4, p.1771-1782, 2002.

ROSTAGNO, H.S.; FEATHERSTON, W.R. Estudos de métodos para determinar disponibilidade de aminoácidos com pintos. Revista Brasileira de Zootecnia, v.6, n.1, p.64-76, 1997.

ROSTAGNO, H.S. Tabelas brasileiras para aves e suínos: composição de alimentos e exigências nutricionais. 2.ed. Viçosa, MG: Editora UFV, 2005. 186p.

ZAVIEZO, D.; CONTRERAS, M. Impacto de hongos y micotoxinas en las aves. Revista Indústria Avícola, v.52, p.19-22, 2005. 